Article

\title{
Impact of Diethyl Ether/Rapeseed Oil Blends on Performance and Emissions of a Light-Duty Diesel Vehicle
}

\author{
Ruslans Smigins * (D) and Arturs Zakis
}

Motor Vehicle Institute, Faculty of Engineering, Latvia University of Life Sciences and Technologies, 5 J.Cakstes blvd., LV3001 Jelgava, Latvia; artursz22@inbox.lv

* Correspondence: ruslans.smigins@llu.lv; Tel.: +371-28-228-222

Received: 1 July 2020; Accepted: 22 July 2020; Published: 23 July 2020

check for updates

\begin{abstract}
This article presents results of experimental study of diesel, rapeseed oil and three different blends of $10 \%, 20 \%$ and $30 \%$ diethyl ether addition to rapeseed oil, tested on VW Golf vehicle on chassis dynamometer Mustang MD-1750. Fuel consumption and emission tests were conducted at different testing conditions: idling, $50 \mathrm{~km} / \mathrm{h}, 90 \mathrm{~km} / \mathrm{h}$, as also IM-240 cycle. The analysis of obtained results have shown reduction of engine power by $6.2 \%-17.3 \%$ and increase of fuel consumption by $0.6 \%-15.5 \%$ (based on testing conditions) for all blends based on DEE addition compared to $\mathrm{RO}$, demonstrating better perspectives for low level blends. Emission tests have shown decrease of hydrocarbons and nitrogen oxides (NOx) for all blends with DEE content in almost all testing conditions and also slight increase of carbon monoxides and carbon dioxides compared to rapeseed oil. Largest decrease of NOx was observed during $90 \mathrm{~km} / \mathrm{h}$ and cycle IM-240 reaching almost $24 \%$ reduction for 20DEE and 30DEE in comparison to neat RO.
\end{abstract}

Keywords: rapeseed oil; diethyl ether; power; fuel consumption; emissions; engine

\section{Introduction}

Based on ecological problems during the last years public opinion according to conventional fossil fuels was changed showing more interest for different alternative fuels, as also electric vehicles. Increasing companies are trying to become greener, which is stimulated also by different cities across the world taking measures on reduction of number of cars in city centers. Such thinking was also reinforced by Volkswagen emission cheating scandal, which has restricted sales of diesel cars in Europe reducing share for diesel cars from 55\% in 2011 to $35.9 \%$ in 2018. Reduction is significant, but it seems that more governmental efforts will be necessary to change habits of one of the largest group of diesel engine users in the world. Besides of that there does not exist stable alternative to diesel engines in several transport sectors (trucks, tractors, locomotives, etc.). Therefore, use of different alternative fuels is still more viable in nearest 10-20 years in existing internal combustion engines. However, it should be noted that retreat of low carbon content fuel alternatives not possible as road transport sector is the largest contributor of total NOx and a significant contributor of CO and primary PM2.5 emissions [1].

Biofuels are still considered as attractive alternatives to fossil fuels for users in many regions due to a simplified adaptation - no necessity for noticeable changes and investments in existing vehicles, as also refueling process is simplified and well known. It cannot be denied that main part of nowadays used biofuels are still compose a list of first generation biofuels, which are primarily derived from feedstocks listed as a food crops, but while advanced biofuels still have many barriers to become essential competitor in fuel market, there always will be consumers, who will use such fuels like rapeseed oil or biodiesel produced from rapeseed oil. 
The use of rapeseed oil is popular in farms and companies, where production of rapeseed forms significant part of the business. It allows to use rapeseed oil produced by themselves in existing vehicles after appropriate modifications. Such modification usually is connected with improvement of fuel system with installation of different additional components: electric fuel preheater, heat exchanger, additional fuel tank, etc. All these improvements are necessary due to a significantly higher viscosity of vegetable oil, which can leave negative impact on the performance and durability of internal combustion engine. High viscosity of vegetable oil contributes poor fuel atomization [2], and as a consequence, result in to low efficient combustion process, injector cooking and fuel pump failure. In such case operation of the vehicle is complicated, especially in winter time, as oil becomes viscous and sticky and results with gelling of fuel lines. Preheating of rapeseed oil requires $120^{\circ} \mathrm{C}$ minimally to achieve the physicochemical properties of conventional diesel fuel used in engines [3] therefore simplified alternative could be mixing vegetable oil with conventional diesel fuel creating mixture, where diesel forms about $30 \%$ by volume.

Previous surveys on use of alternative fuels in Germany [4] shows that it is better if the alternative fuel is compatible with existing vehicle as drivers are not interested to retrofit existing car or buy a new one. Therefore, fuel modification in the way of blending, emulsification or oxygenation is the simplest solution for emission reduction, neither engine modification for alternative fuel use. Furthermore, preheating of oil is not the best solution due to increase of fuel consumption for preheated oils than those without preheating, while no effect of this heating process was noticed on diesel engine opacity [5].

Rapeseed oil, which is the most popular oil type in research in Europe based on its relatively high energy content (7\% lower in comparison to diesel vol.) [6], contains less saturated fatty acid than other oils, therefore it is more suitable to use in cold conditions [7]. Besides of that the use of oil could be problematic in winter due to a weather conditions, when temperature fluctuate between +5 to $-20^{\circ} \mathrm{C}$. Different alcohols (ethanol, butanol, diethyl ether, etc.) can be used as viscosity lowering additives, which can also increase cetane number [8] and improve spray characteristics. Such addition in content till 20\% can ensure diesel engine operation by non-essential modification [9]. Besides of that, oxygen presence in the molecular structure leaves positive impact on reduction of main emission components. Different studies $[10,11]$ confirm that use of ethanol addition can reduce most of regulated emissions and even nitrogen oxide emissions. The use of ethers, which are similar in structure to alcohols, leaves almost equal effect on engine performance and emissions. Diethyl ether (DEE) based on its characteristics (see Table 1)-improved miscibility, higher cetane number, oxygen content, prolonged flammability, [12] — seems to be the most suitable fuel for diesel engine in case of improvement of diesel engine performance, as also emissions, in combination with rapeseed oil. Facing all these advantages it is necessary to look for fuel composition allowing to use potential of both these fuels in diesel engine.

Table 1. Basic parameters of diesel fuel, rapeseed oil and diethyl ether [13,14].

\begin{tabular}{cccc}
\hline Parameter & Diesel & Rapeseed Oil & Diethyl Ether \\
\hline Chemical formula & $\mathrm{C}_{13} \mathrm{H}_{14}$ & $\mathrm{C}_{57} \mathrm{H}_{105} \mathrm{O}_{6}$ & $\mathrm{C}_{4} \mathrm{H}_{10} \mathrm{O}$ \\
Density at $20^{\circ} \mathrm{C}, \mathrm{g} \cdot \mathrm{mL}^{-1}$ & 0.829 & 0.912 & 0.718 \\
Kinematic viscosity at $40{ }^{\circ} \mathrm{C}, \mathrm{mm}^{2} \cdot \mathrm{s}^{-1}$ & 2.68 & 23.91 & 2.3 \\
Lower calorific value, $\mathrm{kJ} \cdot \mathrm{kg}^{-1}$ & 42636 & 36995 & 33900 \\
Cetane number & 51.6 & $44-48$ & $>125$ \\
Flash point, ${ }^{\circ} \mathrm{C}$ & 78 & 244 & -45 \\
Latent heat of vaporization, $\mathrm{kJ} \cdot \mathrm{kg}^{-1}$ & 250 & - & 350 \\
Molecular weight & $180-192$ & 885 & 74 \\
\hline
\end{tabular}

Various studies on DEE use in diesel engines shows that it can be used in different forms-in blends with diesel fuel, biodiesel, biodiesel-diesel blends, ethanol-biodiesel-diesel blends and even with waste plastic pyrolysis oil, which are briefly reviewed in some publications $[15,16]$. Very few works exist on the application experience of DEE mixing with different vegetable oils. Research [17] on selected physicochemical properties of diethyl ether/rapeseed oil blends of $10 \%, 20 \%, 30 \%$ and $40 \%$ by 
volume confirmed that even $10 \%$ DEE addition can reduce viscosity by $50 \%$ in such way improving the atomization of fuel during injection process. Researchers also have found that DEE addition leaves significant impact on the miscibility of all tested blends in a wide range of temperature regimes, as also that they do not stimulate the corrosion processes [17].

Other researchers [18] have made investigations in dual fuel diesel engine with karanja oil blends with DEE. They have used these blends as an oxygenated additive in different proportions till $25 \%$ by volume. Researchers confirmed that DEE addition can significantly reduce NOx emissions, as also made conclusion that tested fuel blends can be used as a commercial fuel with further advancements in the processing techniques and preparation of the fuel [18].

Lotko [19] conducted research with rapeseed oil and its blends with addition of $10-40 \%$ of DEE by volume on AD3.152 engine with conventional fuel injection system. Tests were carried out for 1000, 1500 and $2000 \mathrm{rpm}$ as well as for engine loads of 40,80 and $120 \mathrm{Nm}$. He found that DEE blended with $\mathrm{RO}$ allows the reduction of smoke emission even by $50 \%$ compared to the values obtained with neat rapeseed oil.

Rakopoulos [20] conducted research with diesel fuel, as also various blends with cottonseed oil, ethanol, n-butanol and diethyl ether, where he has found diethyl ether possibility to reduce NOx emissions even better than corresponding blends with n-butanol and ethanol explaining it with relatively lower temperature during combustion. At the same time, the confirmed increase of HC emissions in comparison with diesel explaining it with 'the broadening of the lean spray flame-out region during the relatively higher ignition delay'.

Previous reviews and researches showed many significant advantages of mentioned fuels and blends but results from vehicle tests are very poor do not revealing convincing conclusions in relation to DEE impact on main working parameters of diesel engine, as also variation of main exhaust components. Therefore, the aim of this research was to realize practical study on the use of diethyl ether and rapeseed oil blends in light-duty vehicle with industrial application to investigate impact of such blends on engine performance and emissions.

\section{Materials and Methods}

The impact of diethyl ether added to rapeseed oil on engine performance and selected exhaust components was tested on a VW Golf 1.6 TD vehicle with a 5-speed manual transmission. The choice of the car was made taking into account the relatively high average age for cars in Latvia, which is approximately 13 years. Technical characteristics of the engine are summarized in Table 2 . The engine used in the tests is a 4 cylinder indirect injection compression ignition engine with industrial application.

The schematic diagram of the experimental setup used for studying engine emission characteristics, as also fuel consumption is shown in Figure 1. Fuel consumption was measured on a laboratory chassis dynamometer Mustang MD-1750 by weighting method using electronic scales. MD-1750 chassis dynamometer was used to apply a load to the test vehicle. This allowed to obtained power curve, which was used for engine power analysis with all test fuels. Before tests a car was fastened with straps on a chassis dynamometer Mustang MD-1750, which allows to simulate road and air resistance, as well as realize experiments in different driving cycles. Using power test there was necessary to set measuring range according to the characteristics of the car. The test was conducted at a particular fixed transmission gear and the maximum fuel delivery. The gear selection depends on the specifics of a particular car. Test was started with driving at speed slightly less than the minimum speed set in the control software and further the accelerator pedal needs to be pressed down and kept until the indication on realization of the test was received. The air temperature in the laboratory during the tests was maintained between 16 to $19^{\circ} \mathrm{C}$. 
Table 2. Main characteristics of VW Golf vehicle used for the tests.

\begin{tabular}{cc}
\hline Parameter & Characteristics \\
\hline Name & VW Golf \\
Production year & 1991 \\
Engine capacity & $1588 \mathrm{~cm}^{3}$ \\
Cylinder number and arrangement & 4, in line \\
Cylinder diameter, mm & 76.5 \\
Piston stroke, mm & 86.4 \\
Compression ratio & 23 \\
Max. power & $44 \mathrm{~kW}$ at $4500 \mathrm{rpm}$ \\
Max. torque & 110 Nm at $2600 \mathrm{rpm}$ \\
Charge system & turbocharged \\
Emission control & oxi-catalyst \\
Mileage & $301,328 \mathrm{~km}$ \\
Gear ratios & \\
1st gear & 3.455 \\
2nd gear & 1.944 \\
3rd gear & 1.444 \\
4th gear & 1.129 \\
5th gear & 0.894 \\
\hline
\end{tabular}

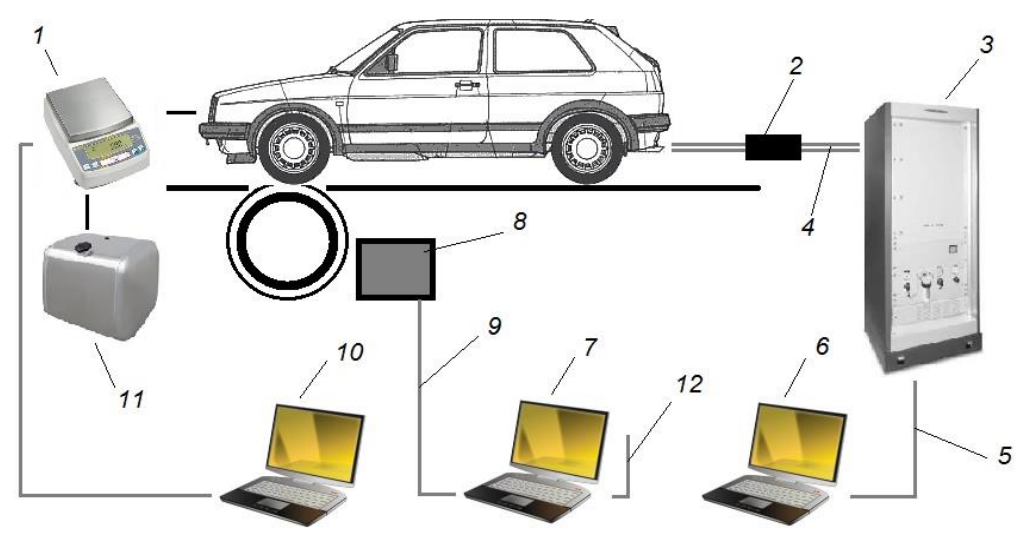

Figure 1. Schematic diagram of the setup used in tests. 1-Electronic scales; 2-heated filter; 3-AVL SESAM FTIR multicomponent measurement system; 4-heated gas line; 5-AVL data communication cable; 6-computer with special AVL software; 7-MD-1750 dyno control and data recording computer; 8-power absorber unit; 9-dyno date communication cable; 10-fuel consumption and data recording; 11-fuel tank; 12-screen communication cable.

Fuel consumption and emission tests were accomplished at most popular vehicle operating conditions: idling, IM-240 cycle, 50 and $90 \mathrm{~km} / \mathrm{h}$. Such speed choice was based on maximum allowed speed limits in urban and suburban areas of Latvia. Sampling rate during constant speed test measurements was maintained constant ( $1 \mathrm{~s})$. Measurement time- 2 min. Additionally was realized a short, combined cycle IM-240 (240 s test), representing $3.1 \mathrm{~km}$ route not only in urban driving conditions, but also non-urban driving conditions.

Emission components were measured by AVL SESAM FTIR multicomponent measurement system able to measure up to 25 gases with acquisition frequency of $1 \mathrm{~Hz}$. During the tests all those gases were recorded as concentrations on a volumetric basis with the aim for detailed analysis only of the most essential regulated exhaust gas components: nitrogen oxides (NOx), carbon monoxide $(\mathrm{CO})$, carbon dioxide $\left(\mathrm{CO}_{2}\right)$ and unburned hydrocarbons $(\mathrm{HC})$. Results were presented as averaged raw measurement values. Relative uncertainty for exact components: $0.22 \%\left(\mathrm{CO}_{2}\right), 0.29 \%(\mathrm{CO})$, $0.5 \%$ (HC, NOx). 
The results of the tests that were replicated three times were averaged in order to decrease the uncertainty and the results were reported. During tests vehicle was tested with all the fuels in random order and the drivability of the vehicle was unimpaired during tests. Measurement errors for all tests were calculated at $95 \%$ confidence level and showed by error bars.

Diesel fuel (DD), meeting EN 590 standard, rapeseed oil (RO) and three blends containing 10\% $(v / v)$ of diethyl ether with $90 \%(v / v)$ of rapeseed oil (mixture code: 10DEE); $20 \%(v / v)$ of diethyl ether with $80 \%(v / v)$ of rapeseed oil (mixture code: $20 \mathrm{DEE}) ; 30 \%(v / v)$ of diethyl ether with $70 \%(v / v)$ of rapeseed oil (mixture code: 30DEE) was used for those tests. Tested blends were prepared just before the experiments by splashing mixing technique in the proportions mentioned before.

Measurements of basic physicochemical properties of mentioned fuels and blends, as also emissions and performance parameters were realized in Alternative Fuels Research Laboratory situated in Latvia University of Life Sciences and Technologies; these properties are listed in Table 3.

Special engine conversion kit was not used during the tests. Neat rapeseed oil used was heated in another fuel tank up to $65^{\circ} \mathrm{C}$ before the injection with the aim to reduce viscosity and ensure engine work properly. Heated fuel tank was not applied for fuel blends containing rapeseed oil.

The environmental impacts of fuel samples were observed also after placing them in an environment with temperature control capabilities (see Figure 2) allowing to identify visual changes of the fuels and blends. Visual observations shows that rapeseed oil and its low-concentration mixture (10DEE) at low ambient temperatures have thickened significantly than it would have been possible in case of 20DEE or even diesel fuel.

Table 3. Technical characteristics of the tested fuels.

\begin{tabular}{ccccccc}
\hline Parameter & DD & RO & 10DEE & 20DEE & 30DEE & DEE \\
\hline Composition DD/RO/DEE, \% volume & $100 /-/-$ & $-/ 100 /-$ & $-/ 90 / 10$ & $-/ 80 / 20$ & $-/ 70 / 30$ & $-/-/ 100$ \\
Kinematic viscosity at $20{ }^{\circ} \mathrm{C}, \mathrm{mm}^{2} \cdot \mathrm{s}^{-1}$ & 2.54 & 54.73 & 25.82 & 13.73 & 9.83 & 0.45 \\
Density at $2{ }^{\circ} \mathrm{C}, \mathrm{g} \cdot \mathrm{cm}^{-3}$ & 0.824 & 0.916 & 0.896 & 0.882 & 0.872 & 0.710 \\
Lower heating value ${ }^{1}, \mathrm{MJ} \cdot \mathrm{kg}^{-1}$ & 42.72 & 37.31 & 37.08 & 36.71 & 36.40 & 33.56 \\
Elements ${ }^{1}, \mathrm{wt} \%$ & & & & & & \\
$\quad$ Carbon & 86.6 & 78.1 & 77.1 & 76.0 & 74.8 & 64.9 \\
Hydrogen & 12.9 & 11.6 & 11.8 & 11.9 & 12.1 & 13.5 \\
Oxygen & 0.5 & 10.3 & 11.2 & 12.1 & 13.1 & 21.6 \\
\hline
\end{tabular}

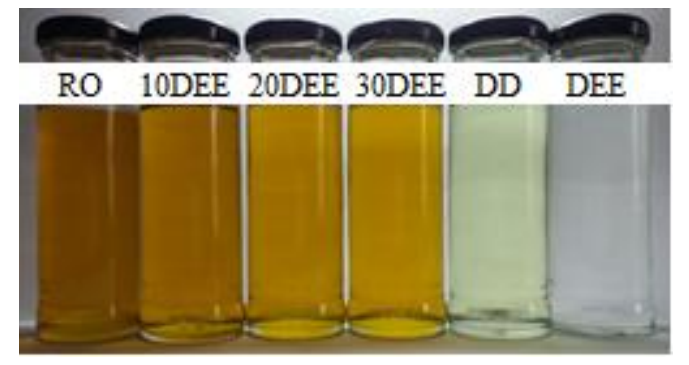

(a)

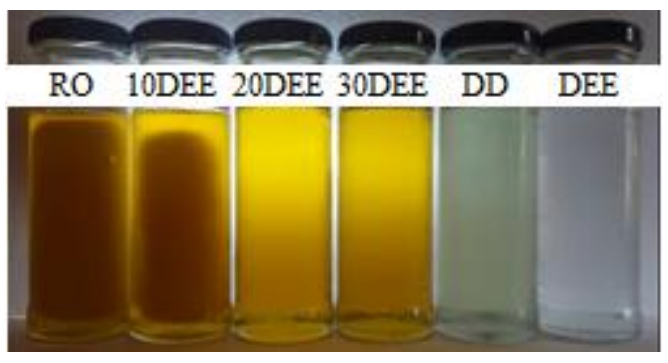

(b)

Figure 2. Fuel samples at different temperatures: $+20^{\circ} \mathrm{C}$ (a) and $-25^{\circ} \mathrm{C}(\mathrm{b})$.

\section{Results and Discussion}

Main results of experimental data of engine performance and emissions using all previously mentioned fuels and blends are summarized in Figures 3-8. Test results confirmed decrease of power with the addition of diethyl ether, which can be attributed to reduction of viscosity and density of the mixture. Maximal values of power were observed directly for RO that is $38.61 \mathrm{~kW}$ at $4200 \mathrm{rpm}$, while other fuels showed decrease from $6.2 \%$ to $17.3 \%$ presenting impact of diethyl ether. Decrease of power by $11.7 \%$ was observed also in case of DD in comparison to RO. Higher viscosity of rapeseed oil 
promotes better sealing of surfaces of plunger pans in older engines in such way reducing leakages. In combination with higher density of $\mathrm{RO}$ it promotes increase of the energy content per unit of volume and additionally increase of the energy delivered per cycle. As systems with mechanical injection control volumetrically apply the fuel in the combustion chamber, therefore this could be reason for increase of power using RO compared to DD. During the tests also was identified that 30DEE gives lower power $(32.4 \mathrm{~kW})$ than DD $(34.7 \mathrm{~kW})$. Similar reduction was observed also in case of torque demonstrating the largest values in case of RO that is $104.21 \mathrm{Nm}$ and reduction for other blends that are 101.06 Nm for 10DEE, $93.80 \mathrm{Nm}$ for 20DEE and 89.12 kW for 30DEE (see Figure 3).

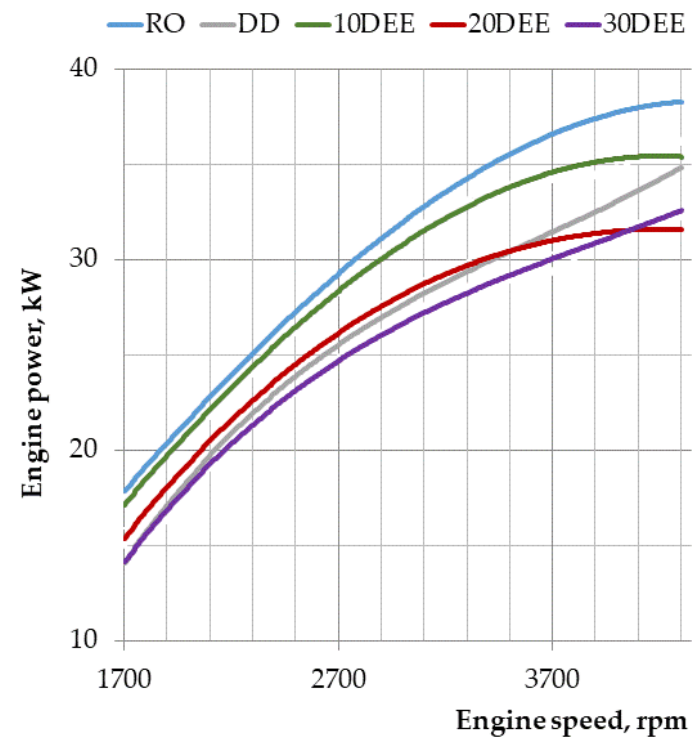

(a)

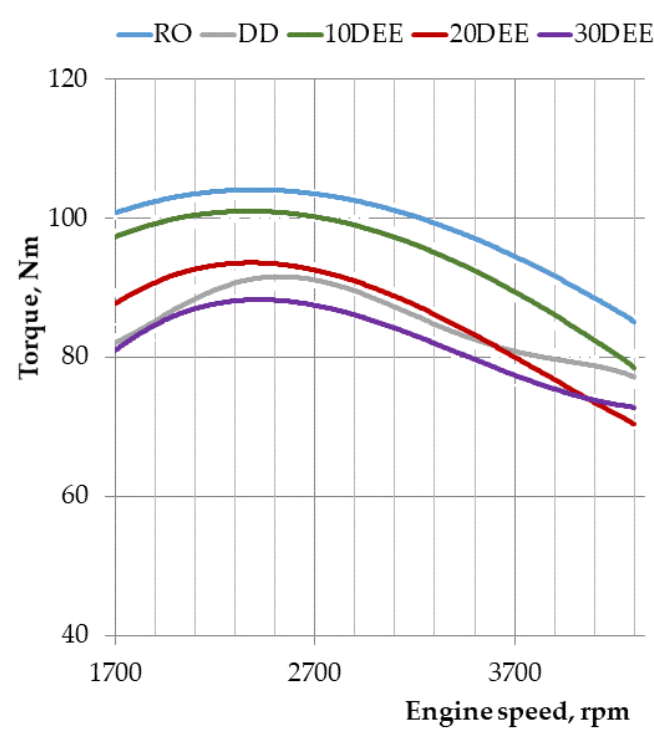

(b)

Figure 3. (a) Engine power and (b) torque curves for different fuels and blends.

Based on the fuel consumption data obtained in experiments and presented in Figure 4, was observed increase in fuel consumption with the addition of diethyl ether in all testing conditions. Results for RO (increase by $2.4 \%$ ) and 10DEE (increase by $4.8 \%$ ) at $50 \mathrm{~km} / \mathrm{h}$ were slightly similar compare to diesel and did not show such rapid increase as in case of 20DEE (increase by $16.8 \%$ ) and 30DEE (increase by 18.3\%). Over the course of further experiments, the difference between blends gradually were decreased, reaching fuel consumption increase by $6.5 \%$ (10DEE), $6.6 \%$ (20DEE) and $14.7 \%$ (30DEE) compared to diesel at $90 \mathrm{~km} / \mathrm{h}$.

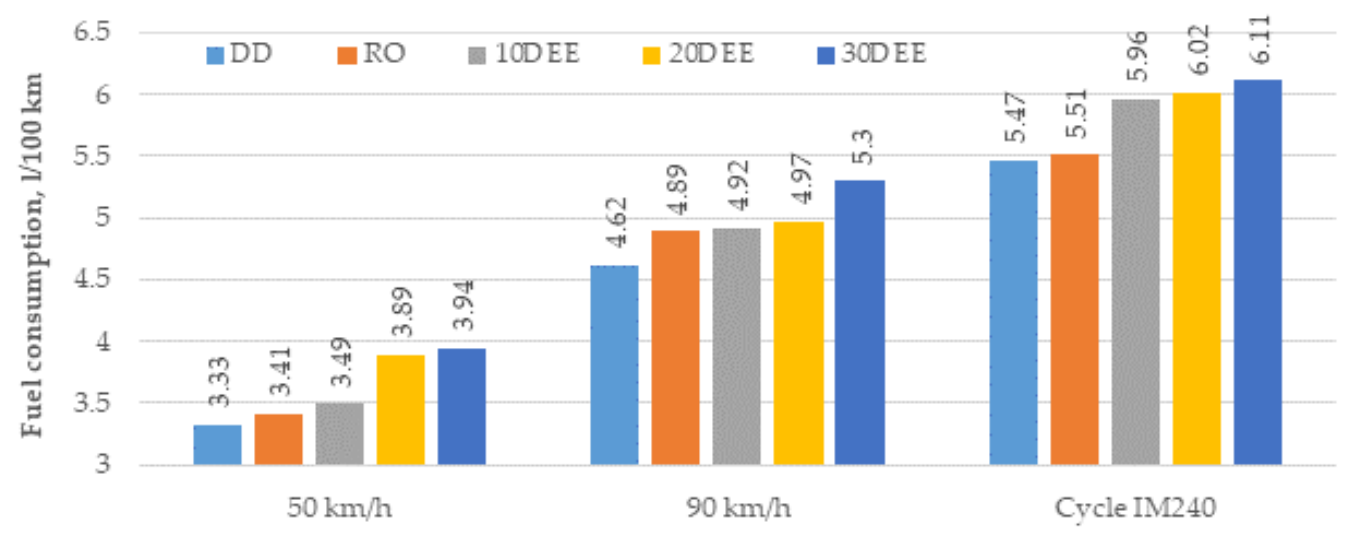

Figure 4. Fuel consumption of diesel fuel (DD), rapeseed oil (RO) and DEE/RO blends. 
During a cycle IM240 fuel consumption increased by $8.9 \%$ (10DEE), 10.1\% (20DEE) and 11.7\% (30DEE) in comparison to DD. Increase of fuel consumption can be explained by lower heating value and further reduction in thermal efficiency of each additional RO-DEE blend instead of RO or DD.

Positive effect of diethyl ether addition first, can be observed according emission reduction due to its oxygen content (see Table 2), which favors the further improvement of RO combustion. This is confirmed also in current tests, where was found considerable decrease of HC emissions in almost all testing conditions, as also slight reduction of $\mathrm{CO}$ at idling and $50 \mathrm{~km} / \mathrm{h}$ compared to RO.

Main decrease of carbon monoxide, measured as molar concentration per mole of exhaust gases, was noticed in idling almost by $43 \%$ adding $30 \%$ of DEE to RO, while in other conditions the gap slightly narrows down (Figure 5). Slight reduction of values for almost all tested blends were registered at $50 \mathrm{~km} / \mathrm{h}$ and increase- -at $90 \mathrm{~km} / \mathrm{h}$ and IM240.

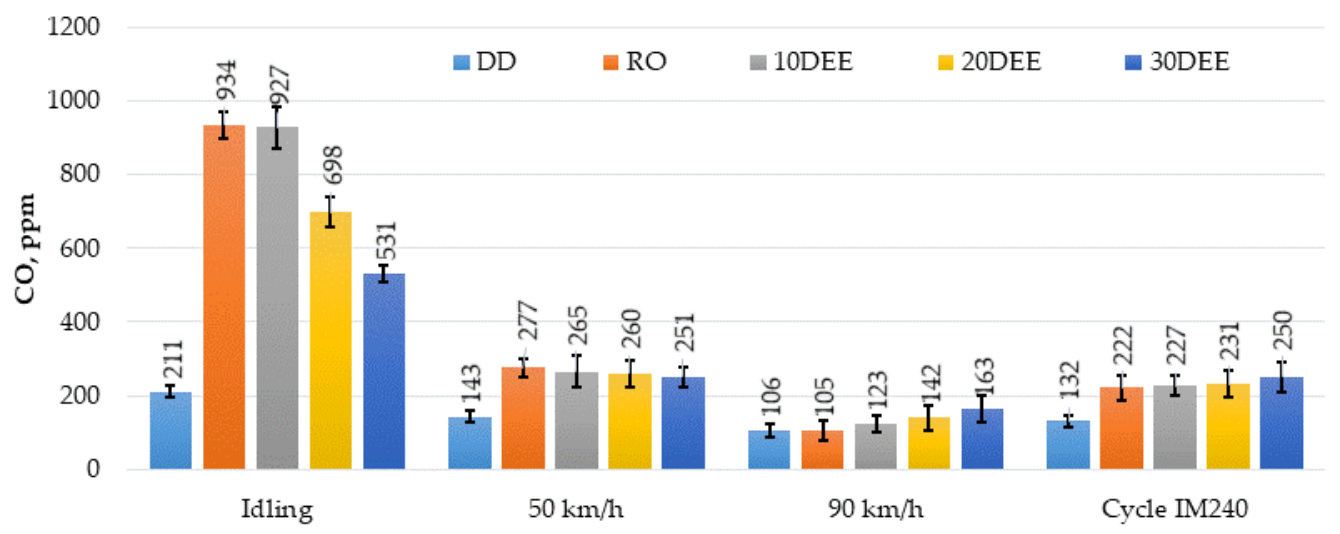

Figure 5. CO emissions of DD, RO, 10DEE, 20DEE and 30DEE in different testing conditions.

Slight increase till 7.3\% in $\mathrm{CO}_{2}$ emissions using DEE blends compared to $\mathrm{RO}$ also was observed in definite testing conditions, but in overall results for all used blends and fuels were almost similar (see Figure 6). It can be ascribed to inbuilt fuel bound oxygen of DEE, which takes reaction with the unburned carbon atoms, oxidation rate improves resulting in higher $\mathrm{CO}_{2}$ formation in case of DEE blends. This can be more pronounced in higher engine loads. In any case additional factors, like $\mathrm{C} / \mathrm{H}$ ratio, elemental carbon, mixture density and total available oxygen, for $\mathrm{CO}_{2}$ formation should be taken into account [12].

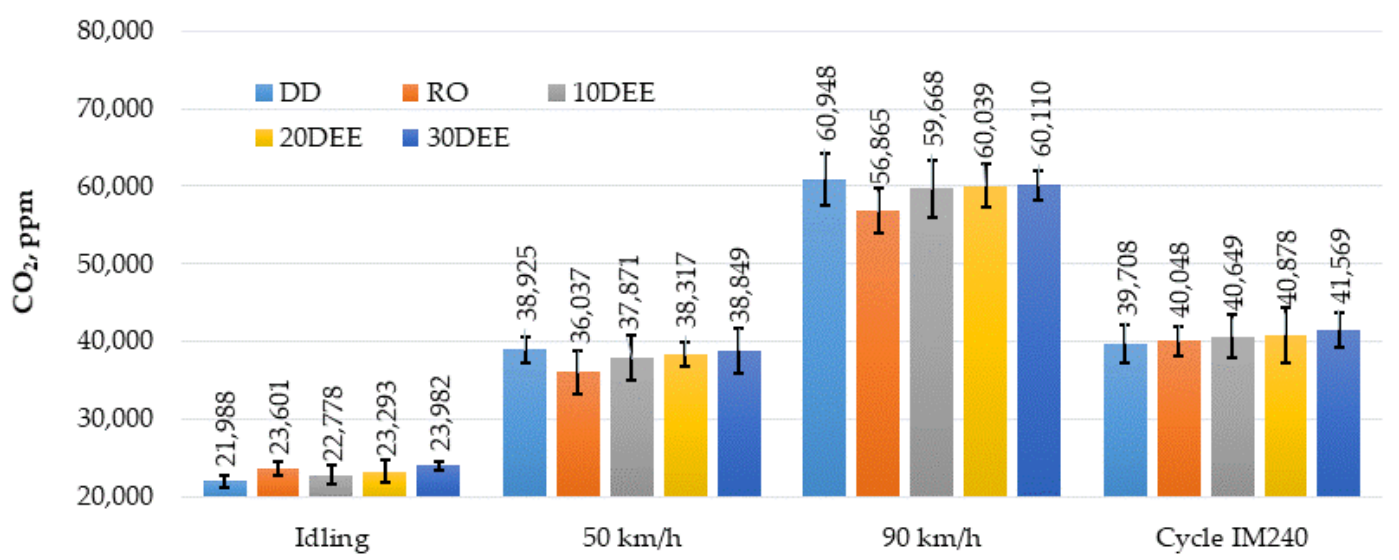

Figure 6. $\mathrm{CO}_{2}$ emissions of DD, $\mathrm{RO}, 10 \mathrm{DEE}, 20 \mathrm{DEE}$ and 30DEE in different testing conditions.

Similar situation was noticed also with hydrocarbons presenting more pronounced reduction in all realized tests, but best results in case of 20DEE are 31.5\% (at idling), $62.7 \%(50 \mathrm{~km} / \mathrm{h}), 72.6 \%(90 \mathrm{~km} / \mathrm{h}$ ) and $78.8 \%$ (at cycle IM-240) compared to RO (see Figure 7). In the same time DEE addition to rapeseed 
oil demonstrates higher HC emissions in comparison to DD. It is known that formation of hydrocarbons in the engine is very complicated and is accompanied by various factors. However, it is primarily connected with incomplete combustion generated by flame cooling and inappropriate air-fuel mixture, as also can be affected by fuel structure, operating conditions and engine load. Existence of oxygen in the chemical structure of DEE allows to reduce HC emissions more slightly depend on DEE concentration in blend. Hence, largest HC decrease was observed using 20DEE and 30DEE blends. Higher emissions sometimes using DEE blends can be observed by creation lean outer flame zone, especially in IDI engines, which are more disposed to homogenous charge. Overmixing created directly by fuels with lower density and viscosity, promote stays beyond the flammability limit [21].

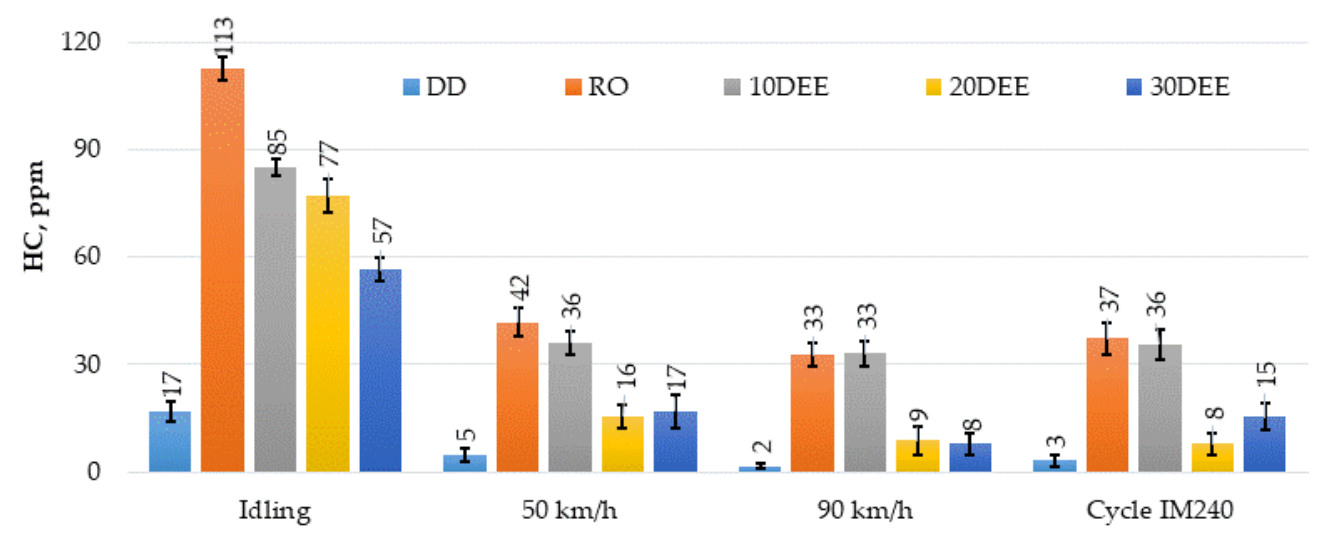

Figure 7. HC emissions of DD, RO, 10DEE, 20DEE and 30DEE in different testing conditions.

There was also observed decrease of NOx emissions for all mentioned fuels and testing conditions. Largest decrease was observed during $90 \mathrm{~km} / \mathrm{h}$ and cycle IM240 reaching $22.1 \%$ to $23.9 \%$ reduction for 20DEE and 30DEE (see Figure 8) in comparison to neat RO. Such decrease in NOx emissions can be explained by lower combustion temperature due to a low heating value and high latent heat of vaporization of DEE, in such way cooling the intake charge and reducing the peak flame temperature and additionally NOx. Prevalence of lower peak cycle temperature was considered as a reason for not favoring the thermal prompt reactions responsible for the formation of higher levels of NOx [22]. Such reduction can be more rapid with increase of the percentage of diethyl ether in the blend and is detected by other researchers [23].

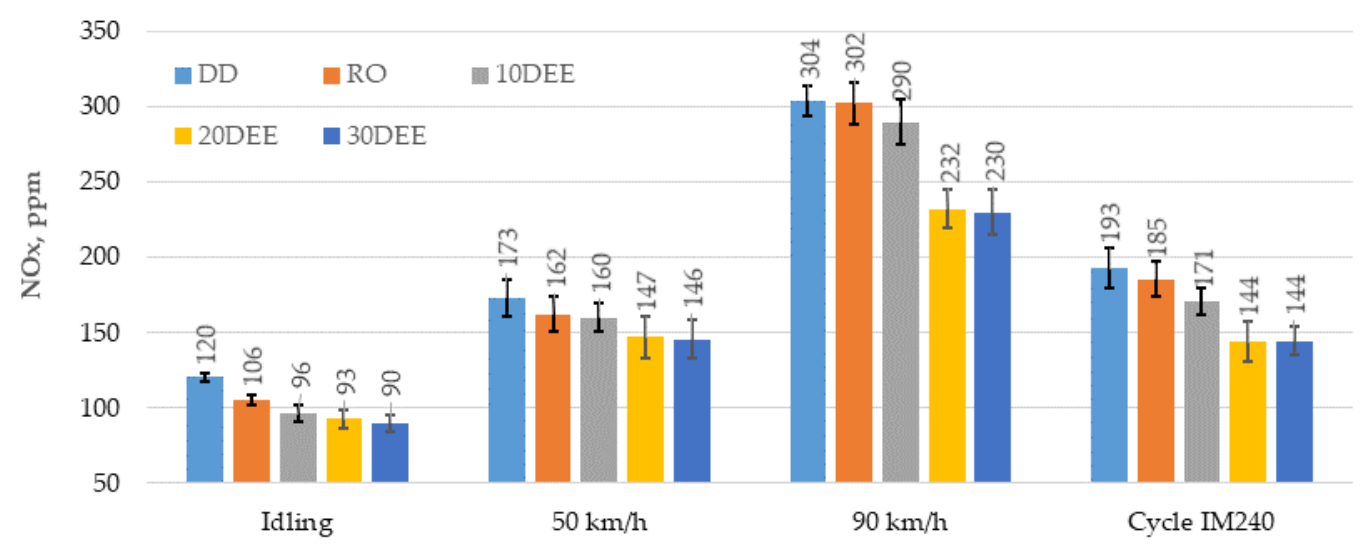

Figure 8. NOx emissions of DD, RO, 10DEE, 20DEE and 30DEE in different testing conditions.

It cannot be denied that NOx emissions are directly connected with temperature in cylinder therefore temperature lowering effect of diethyl ether has the prevailed impact in most cases providing more zones in cylinder close to stoichiometric conditions [24]. There exists also other reasons for NOx variation, mentioned by researchers $[25,26]$. Inessential gap in NOx observed during tests 
between 20DEE and 30DEE blends can be ascribed also to more absolute combustion of the fuel-air mixture resulted by additional oxygen [26]. In any case further research of combustion parameters are recommended.

Furthermore, it was observed that mixture richer than $20 \%$ of DEE affected engine starting-too high temperature caused intensive vaporization of DEE in low pressure line. Therefore, research with DEE addition with more than $30 \%$ was not realized and not recommended.

\section{Conclusions}

The results of this research showed positive tendency in diethyl ether addition to RO in case of NOx and HC emission reduction, but it also confirmed that diethyl ether promotes slight increase of $\mathrm{CO}$ and $\mathrm{CO}_{2}$ in comparison to rapeseed oil. Increase of fuel consumption and decrease of power should be expected based on volume of DEE added to RO. The above observation according fuel consumption confirms that lower heating value and further reduction in thermal efficiency dominates for each additional RO-DEE blend instead of RO or DD.

Low level DEE-RO blends, like 10DEE (10\% diethyl ether $+90 \%$ rapeseed oil) and 20DEE ( $20 \%$ diethyl ether $+80 \%$ rapeseed oil) are the most suitable ratios due to acceptable fuel related properties (density, viscosity, lower heating value, improved miscibility) and engine performance, as also reduction of emissions. Increase of oxygen content and improvement of fuel related properties of DEE/RO blends with increase of DEE addition allows to draw up to the limit values of those blends close to diesel fuel. Variation of exact ratio depends on outside temperature, where vehicle will be used. Higher level blends, like 30DEE, gives substantial increase in fuel consumption and decrease in engine power and therefore do not maintain its economic feasibility as a fuel component. Besides of that the use of 30DEE can discover problems with engine starting, which was observed during the tests.

In overall DEE has some essential advantages over other fuels-its physicochemical composition can be perfect solution neither in assistance of improvement of engine performance and emissions, but also in avoiding of cold start problems of the engine in regions where outside temperature is close to zero degrees Celsius most part of the year. Based on those arguments showing clear advantages of DEE, more detailed study on other vegetable oil and DEE composition should be conducted for search of other feasible alternatives. Finally, it would be necessary to carry out more extensive outdoor studies using portable emission measurement system (PEMS) and high precision fuel consumption measurement system (AVL KMA Mobile) for fuel consumption and emission detection on the road to verify the vehicle's ability to operate at different ambient temperatures.

Author Contributions: Methodology, supervision, writing-original draft preparation, R.S.; formal analysis, investigation, visualization, R.S., A.Z.; writing-review and editing, R.S., A.Z.; critical revision of the article, R.S. All authors have read and agreed to the published version of the manuscript.

Funding: This research received no external funding.

Conflicts of Interest: The authors declare no conflicts of interests.

\section{References}

1. European Environmental Agency. Available online: https://www.eea.europa.eu/publications/air-quality-ineurope-2018 (accessed on 6 March 2020).

2. Honig, V.; Hromadko, J. Possibilities of using vegetable oil to power diesel engines as well as their impact on engine oil. Agron. Res. 2014, 12, 323-332.

3. Esteban, B.; Riba, J.R.; Baquero, G.; Rius, A.; Puig, R. Temperature dependence of density and viscosity of vegetable oils. Biomass Bioenergy 2012, 42, 164-171. [CrossRef]

4. Linzenich, A.; Arninga, K.; Bongartz, D.; Mitsos, A.; Ziefle, M. What fuels the adoption of alternative fuels? Examining preferences of German car drivers for fuel innovations. Appl. Energy 2019, 249, 222-236. [CrossRef] 
5. Delalibera, C.H.; Johann, A.L.; De Figueiredo, P.R.A.; De Toledo, A.; Weirich Neto, P.H.; Ralisch, R. Performance of diesel engine fuelled with four vegetable oils, preheated and at engine working temperature. J. Braz. Assoc. Agric. Eng. 2017, 302-314. [CrossRef]

6. Hemmerlein, N.; Korte, V.; Richter, H. Performance, exhaust emissions and durability of modern diesel engines running on rapeseed oil. SAE Int. Congr. Expo. 1991, 100, 910848.

7. Sawaki, T.; Shibuya, Y.; Miyata, Y.; Noguchi, N. Application of rapeseed oil to a diesel engine. IFAC Proc. Vol. 2010, 43, 215-218. [CrossRef]

8. Holubek, M.; Pexa, M.; Cedik, J.; Mader, D. Effect of long-term operation of combustion engine running on n-butanol-Rapeseed oil-Diesel fuel blend. Agron. Res. 2019, 17, 1001-1012. [CrossRef]

9. Agarwal, A.K. Biofuels (alcohols and biodiesel) applications as fuels for internal combustion engines. Prog. Energy Combust. Sci. 2007, 33, 233-271. [CrossRef]

10. Giakoumis, E.G.; Rakopoulos, C.D.; Dimaratos, A.M.; Rakopoulos, D.C. Exhaust emissions with ethanol or n-butanol diesel fuel blends during transient operation: A review. Renew. Sustain. Energy Rev. 2013, 17, 170-190. [CrossRef]

11. Smigins, R. Perspectives of low level ethanol and biodiesel/diesel fuel blends on diesel engine emission reduction. In Proceedings of the 20th International Scientific Conference on Transport Means, Juodkrante, Lithuania, 5-7 October 2016; pp. 337-341.

12. Venu, H.; Madhavan, V. Influence of diethyl ether (DEE) addition in ethanol-biodiesel-diesel (EBD) and methanol-biodiesel-diesel (MBD) blends in a diesel engine. Fuel 2017, 189, 377-390. [CrossRef]

13. Qi, D.H.; Lee, C.F.; Jia, C.C.; Wang, P.P.; Wu, S.T. Experimental investigations of combustion and emission characteristics of rapeseed oil-diesel blends in a two cylinder agricultural diesel engine. Energy Convers. Manag. 2014, 77, 227-232. [CrossRef]

14. Bailey, B.; Eberhardt, J.; Goguen, S.; Erwin, J. Diethyl ether (DEE) as a renewable diesel fuel. SAE Tech. Pap. 1997, 972978. [CrossRef]

15. Devaraj, J.; Robinson, Y.; Ganapathi, P. Experimental investigation of performance, emission and combustion characteristics of waste plastic pyrolysis oil blended with diethyl ether used as fuel for diesel engine. Energy 2015, 85, 304-309. [CrossRef]

16. Krishnamoorthi, M.; Malayalamurthi, R. A review on effect of diethyl ether additive on combustion, performance and emission characteristics of a diesel and biodiesel/vegetable oil fuelled engine. Adv. Nat. Appl. Sci. 2016, 10, 9-17.

17. Gorski, K.; Smigins, R. Selected physicochemical properties of diethyl ether/rapeseed oil blends and their impact on diesel engine smoke opacity. Energy Fuels 2018, 32, 1796-1803. [CrossRef]

18. Krishna, R.; Banderwar, A.G.; Dongare, V.K. Experimental investigations of blending diethyl ether in karanja vegetable oil using a multi-cylinder diesel engine. Int. J. Res. Innov. Technol. 2014, 1, 70-73.

19. Lotko, W.; Hernik, A.; Stobiecki, J.; Kosmanis, T.; Gorska, M. Smoke emission of AD3.152 engine fuelled with rapeseed oil/diethyl ether blends. Arch. Automot. Eng. Arch. Motoryz. 2018, 80, 65-76. [CrossRef]

20. Rakopoulos, D.C.; Rakopoulos, C.; Giakoumis, E.G.; Papagiannakis, R.G.; Kyritsis, D.C. Influence of properties of various common bio-fuels on the combustion and emission characteristics of high-speed DI (direct injection) diesel engine: Vegetable oil, bio-diesel, ethanol, n-butanol, diethyl ether. Energy 2014, 73, 354-366. [CrossRef]

21. Imtenan, S.; Masjuki, H.H.; Varman, M.; Kalam, M.A.; Arbab, M.I.; Sajjad, H. Impact of oxygenated additives to palm and jatropha biodiesel blends in the context of performance and emissions characteristics of a light-duty diesel engine. Energy Convers. Manag. 2014, 83, 149-158. [CrossRef]

22. Prasad, U.; Madhu, K.; Amba, G. Effect of oxygenated additives on control of emissions in a DI diesel engine using biodiesel-diesel blends. In Proceedings of the International Conference on Mechanical, Automobile and Robotics Engineering, Penang, Malaysia, 11-12 February 2012; pp. 256-260.

23. Imtenan, S.; Masjuki, H.H.; Varman, M.; Rizwanul, I.M.; Sajjad, H.; Arbab, M.I. Effect of n-butanol and diethyl ether as oxygenated additives on combustion-emission-performance characteristics of a multiple cylinder diesel engine fuelled with diesel-jatropha biodiesel blend. Energy Convers. Manag. 2015, 94, 84-94. [CrossRef]

24. Heywood, J.B. Internal Combustion Engine Fundamentals; McGraw-Hill: New York, NY, USA, 1988. 
25. Rakopoulos, C.D.; Antonopoulos, K.A.; Rakopoulos, D.C. Development and application of a multi-zone model for combustion and pollutants formation in a direct injection diesel engine running with vegetable oil or its bio-diesel. Energy Convers. Manag. 2007, 248, 1881-1901. [CrossRef]

26. Sezer, I. A review study on the using of diethyl ether in diesel engines: Effects on NOx emissions. Int. J. Automot. Eng. Technol. 2018, 164-183. [CrossRef] 